\title{
Rethinking Global Climate Change Governance
}

\author{
Scott Barrett \\ Johns Hopkins University, School of Advanced International Studies
}

\begin{abstract}
This paper explains why the approach taken so far to mitigate global climate change has failed. The central reason is an inability to enforce targets and timetables. Current proposals recommending even stricter emission limits will not help unless they are able to address the enforcement deficit. Trade restrictions are one means for doing so, but trade restrictions pose new problems, particularly if they are applied to enforce economy-wide emission limitation agreements. This paper sketches a different approach that unpacks the climate problem, addressing different gases and sectors using different instruments. It also explains how a failure to address the climate problem fundamentally will only create incentives for different kinds of responses, posing different challenges for climate change governance.
\end{abstract}

Special issue "Global Governance—Challenges and Proposals for Reform” Published as Policy Paper

JEL: F18, F51, F53, Q54

Keywords: Climate change; Kyoto protocol: enforcement; trade restrictions; R\&D

Correspondence: Scott Barrett, Paul H. Nitze School of Advanced International Studies, Johns Hopkins University, 1717 Massachusetts Avenue, NW, Washington, DC 20036, United States; e-mail:. sbarrett@jhu.edu

Presented at a Symposium on "Global Governance - Proposals for Reform" on the occasion of the $70^{\text {th }}$ birthday of Professor Horst Siebert, Kiel, Germany, June 18, 2008. 


\section{Introduction}

By any reasonable measure, the steps taken so far to address climate change have failed. In 1988, at a quasi-political conference held in Toronto, participants concluded that global carbon dioxide $\left(\mathrm{CO}_{2}\right)$ emissions should be reduced 20 percent from the 1988 level by 2005. Through 2004, however, and despite two climate treaties having entered into force, and numerous unilateral targets having been declared, global emissions increased 32 percent. $^{1}$ A gap this big (50 percent), opening up over a period this short, should make negotiators rethink their approach. So should the observation that atmospheric concentrations have increased every year since measurements began in the late-1950s. Neither trend will change as the Kyoto Protocol is implemented.

The approach taken thus far has been to set economy-wide targets and timetables. This approach would be ideal were it possible to regulate the world's greenhouse gas emissions in top-down fashion. Unfortunately, however, the world's governance arrangements have to work from the bottom up. The world does not have one government; it has nearly 200. An agreement to reduce emissions must not only be attractive from the perspective of the global good. It must also be something to which countries individually want to accede and to adhere. In this article I explain why the approach taken thus far has failed, and how a different approach could work much better.

\section{Background}

What should be the goal of climate change policy? Not doing something about climate change will have implications for current and future generations, but so will doing something about climate change. Economics tries to weigh both sides of this equation. There is broad agreement among economists that emissions should be reduced today below the "business as usual level." (There is disagreement about the precise cut in emissions that is justified). There is also broad agreement that concentrations of greenhouse gases should eventually be stabilized. (There is disagreement about what this stabilization level should be and when it should be reached.) ${ }^{2}$

Stabilization requires that the atmosphere and the oceans be in chemical balance. Over time, take up by the oceans will decline as emissions fall. In equilibrium, if concentrations are to be stabilized, net emissions will have to fall to zero. There is only one way in which this can be done in a manner acceptable to the majority of any country's electorate. Eventually, there must be a technological revolution. ${ }^{3}$ A future treaty arrangement must have its eye on this long run objective. The approach so far has been to focus on an objective expressed in terms of concentration levels (perhaps with the further goal in mind of limiting temperature change). Since concentrations are

\footnotetext{
1 See http://cdiac.ornl.gov/ftp/ndp030/global.1751_2004.ems.

2 For two contrasting views, see Nordhaus (2007) and Stern (2007).

3 See Hoffert et al. (2002).
} 
determined by net emissions, this has led negotiators to express short-term objectives in terms of individual country emission limits.

Unfortunately, the emissions of each country are such a small fraction of the total that the incentives for countries to act unilaterally are modest. Making matters worse, as some countries reduce emissions, comparative advantage in the greenhouse-gasintensive industries will shift to other countries, causing their emissions to increase. To business, this represents a loss in "competitiveness." To environmentalists, it represents emissions "leakage." For both reasons - to deter free riding and prevent leakageinternational cooperation is needed. This will need to take the form of a treaty-perhaps even a system of treaties.

To be successful, a treaty must fulfill three conditions: First, it must attract broad participation. At a minimum, a treaty to limit emissions must include the U.S., the EU, Japan, Russia, China, and India. Second, it must ensure compliance. Finally, it must do both of these things even as it asks its parties to change their behavior substantially. It is easy for a treaty to meet one or two of these conditions. It is very hard for a treaty to do all of them. Kyoto fails to do any of them.

\section{$3 \quad$ Kyoto's Failures}

Kyoto has failed to attract broad participation. It has, in particular, failed to make the United States want to participate. It is easy to blame the Bush administration for this. However, the U.S. Senate voted on a non-binding resolution in July 1997, before Kyoto was negotiated, saying that the U.S. should not be a signatory to any treaty that "would result in serious harm to the economy of the United States" or that would not mandate "new specific scheduled commitments to limit or reduce greenhouse gas emissions for Developing Country Parties within the same compliance period.” This non-binding vote passed 95-0. Hence, it was clear even before Kyoto was negotiated that the U.S. would not ratify it.

Kyoto has also failed to ensure that the countries that ratified it will comply. Canada is a party to the Kyoto Protocol, obligated to reduce its emissions 6 percent below the 1990 level through 2008-2012. In 2005, however, Canada's emissions were 30 percent above this target, and Canada's current government has given up on the idea of meeting the Kyoto target. It aims instead to reduce the rate of growth in emissions, hoping that its emissions will peak around Kyoto's mid-point, 2010. Even this limited ambition appears optimistic; a government-funded roundtable has concluded that the government's own policies will not meet even this modest goal. ${ }^{4}$ Canada's previous government - the one that ratified the agreement but that did not adopt the policies needed to meet its goals-predicted that Canada's emissions would exceed the Kyoto target by 45 percent by $2010 .^{5}$ This prediction may still be close to the mark.

Kyoto has failed to get its parties to take substantial action. Participation in the Framework Convention on Climate Change is nearly full (the only non-participants are Andorra, the Holy See, Iraq, and Somalia). Moreover, compliance with this agreement

\footnotetext{
${ }^{4}$ For the relevant section of the roundtable's report, see http://www.nrtee-trnee.ca/eng/publications/c288response-2007/section4-c288-response-2007-eng.html.

5 Government of Canada (2005).
} 
is perfect. But this agreement does not require that parties reduce their emissions. The Framework Convention is an example of a treaty that fulfils two of the three conditions needed for success.

Kyoto aimed to achieve more but it has had to succumb to the same pressures that caused the Framework Convention to be diluted. China, and India are parties to the Kyoto Protocol, and both countries will comply fully with that agreement, but this is only because Kyoto does not require that they reduce their emissions. Russia and the economies in transition were given a surplus of emissions-environmentalists call it "hot air." For them, the emission constraints do not bite. Getting these countries to participate in Kyoto hardly qualifies for success.

Other countries are required by Kyoto to reduce their emissions, but that does not mean that the treaty will impel them to do so.

The reason Canada will not comply is that Kyoto requires that Canada reduce its emissions substantially. Compliance will also be difficult for New Zealand, which has yet to develop a policy for meeting its obligations, and Japan, which claims to have done a lot to reduce its emissions but is still a long way from meeting its target. Although the government has not conceded as much, there is a good chance that Japan, host to the Kyoto negotiations, will not end up complying.

Compliance by some members of the European Union also appears challenging. Spain has the largest gap of any country. Denmark is well off its individual target. However, thanks to the European "bubble," and substantial reductions by other EU countries (in part for reasons having nothing to do with their climate change policies), these countries are not bound by their individual limits so long as the original 15 members of the European Union meet their collective limit. Australia recently ratified the Kyoto Protocol, but because of the provision for land use, land-use change, and forestry (known to climate insiders as LULUCF), Australia is within its Kyoto limit; Australia will have to do very little if anything to comply. ${ }^{6}$

A look back at the negotiations that continued after 1997 shows a similar pattern of countries seeking to ease their obligations or their need to fulfil their obligations. After the U.S. announced that it would not ratify Kyoto, Canada and Japan insisted upon a generous accounting of their "sinks" (that is, LULUCF) as a condition for their ratification. (Russia, already given a gift of "hot air," also held out for more. On top of that, Russia insisted on obtaining EU support for its accession to the World Trade Organisation.) This renegotiation of the treaty succeeded in bringing the agreement into force, but at the cost of reducing the environmental effectiveness of the agreement - an example of one condition for success being sacrificed for another. Today, compliance can still be achieved fairly easily by means of the Protocol's "flexible mechanisms," thanks to post-1997 negotiations lifting restrictions on trading (again, following on the decision by the U.S. not to ratify). But if compliance is achieved by the purchase of "hot air," emissions may not fall at all. Under these circumstances, it is hard to see why a country would seek to comply using this option (why pay to comply when the payment will not help meet the aim of the two climate treaties?)-another reason why compliance by some countries is in jeopardy.

6 LULUCF is normally treated differently from emissions because of various accounting and incentive problems. For example, carbon accumulated in forestry may later be released. 
There is a tendency for countries within their Kyoto limits to cast themselves as having been more effective at fulfilling their obligations. But the base year for calculating the Kyoto limits (1990) favoured some countries over others. If attention focused on the actions states have taken rather than on whether they have or have not stayed within their Kyoto limits, the differences among states would not appear as great. More importantly, from the perspective of the climate, the emissions of individual states are irrelevant. Success as regards the climate should be measured in terms of global emissions (even better, atmospheric concentrations), and as mentioned earlier these trends are in the wrong direction.

\section{The Failure of U.S. Leadership}

Lack of U.S. leadership has also held back global progress. As already suggested, it is simplistic to view U.S. non-participation in the Kyoto Protocol as exceptional. At the same time, the United States has failed to provide leadership and that has been a setback for the whole world. To be specific, the U.S. has failed: (1) to negotiate a treaty it could get ratified; (2) to adopt meaningful domestic legislation to address climate change; (3) to offer an alternative to Kyoto. The administration of George W. Bush has championed the role of R\&D and helped create the Asia-Pacific Partnership on Clean Development and Climate (the other members of which include Australia, Canada, China, India, Japan, and South Korea), but all these efforts have so far achieved nothing. As just one example, the Bush administration recently cancelled plans for its FutureGen pilot "clean coal” plant, citing cost overruns of $\$ 900$ million. The world has reason to expect more from a superpower.

The next administration will take this issue seriously. However, U.S. leadership on this issue is only a necessary condition for making progress; it is not sufficient. The most important impediment to progress is the need to enforce a future climate change agreement.

\section{The Essential Role of Enforcement}

The following example illustrates the importance of enforcement: In 2002, the United States imposed tariffs on steel imports. The European Union, supported by other countries, complained to the World Trade Organization (WTO), which ruled that the U.S. tariffs violated WTO rules. Under those rules, the EU is permitted to "rebalance" the effect of the U.S. tariffs, should the U.S. fail to remove its tariffs. The U.S. refused to comply with the WTO ruling, and so the EU put together a tariff package that would rebalance the U.S. tariff. The EU tariffs targeted politically sensitive products like citrus fruit from Florida - an astute calculation, since the EU tariffs were to be imposed in December 2003, less than a year before the next U.S. presidential election (recall that Florida was a "battleground" state in the contested 2000 election). Shortly before the EU tariffs were to be imposed, President George W. Bush lifted the tariffs on steel imports. The EU never imposed their tariffs against the U.S.; the credible threat that it would do so was enough to make the U.S. want to comply with the WTO ruling. 
This trade agreement works; it changes how states behave. It made it in the interests of the EU to punish the U.S., and it made it in the interests of the U.S., when facing this punishment, to comply. ${ }^{7}$ The agreement also created incentives for both countries to remain within the agreement. The Kyoto Protocol provides neither kind of incentive.

Rather than focus on building in such mechanisms, negotiators have responded to past failures by seeking to negotiate tougher emission caps. In Bali, the EU pushed for rich countries to cut their emissions 25-40 percent. This proposal is consistent with the view that the problem with Kyoto is that its caps are too generous. Certainly, emissions must be reduced more substantially, but would Kyoto have been more successful if the caps had been harder to meet? Would that have made US participation more likely? Would that have made Canada more inclined to comply? The problem with Kyoto lies in its design, not (only) in its targets. In particular, the problem lies with the difficulty of enforcing emission caps.

Kyoto's caps were negotiated in December 1997, but important details continued to be negotiated for years after that. A compliance mechanism was agreed in 2001. But according to Article 18 of the Kyoto Protocol, any mechanism for enforcing compliance "entailing binding consequences" must be approved by amendment. An amendment is a like a new agreement. It would only be binding on the parties that ratified it, provided at least three-quarters of the parties to the Kyoto Protocol also ratified it. So far, no such amendment has been adopted. The mechanism agreed in 2001 is thus non-binding.

Even if the mechanism were binding, it would have no effect. The main component of the mechanism is a 30 percent penalty. A country that emits, say, 100 tons more than the treaty allows in the first "commitment period" (2008-2012) must make up for this by reducing its emissions by an additional 130 tons (the extra 30 tons being the penalty) in the next period (2013-2017?). This reduction is "additional" relative to this country's next-period cap. This cap, however, is subject to the approval of the country having to pay the penalty. That country can therefore insist on a generous cap as a condition for participating, and so get away with paying a "phantom" penalty. Alternatively, it could ratify the new treaty and then fail to comply again - the current arrangement essentially carries forward the penalty indefinitely. The reason this penalty system cannot deter non-compliance is that its punishments must be self-inflicted. That, of course, is not true of the WTO punishments.

There is one exception to this. Kyoto's non-binding compliance mechanism also allows other countries to suspend a country's trading privileges. Is this punishment credible? Would other countries impose this punishment? There is good reason to believe they would not. ${ }^{8}$ If a large seller of permits were in non-compliance, withdrawal of its trading privileges would push up international permit prices, harming net importers; these countries may be unwilling to impose the punishment. If a large buyer of permits were punished in this same way, international permit prices would fall, harming net exporters; these countries may be unwilling to impose the punishment. In short, the threat to punish may not be credible. Of course, in each of the cases I just mentioned, there would also be some countries that would gain by imposing the

\footnotetext{
7 This is not to say that the WTO is flawless. For example, it is a problem that the U.S. found it in its interests to violate the trading rules in the first place. The incentive for the U.S. to do so is probably due to the long lag between tariffs between imposed and rebalancing being threatened.

8 See Kallbekken and Hovi (2007).
} 
punishments (net exporters in the first instance, net importers in the second). But with some countries gaining and some losing, activation of the sanction may spark conflict among the countries that had complied.

Note that the situation described here is similar to the challenge members of the Euro zone faced in enforcing the Stability and Growth Pact. The enforcement mechanism in this agreement was not credible. ${ }^{9}$

Since, as explained earlier, the WTO is enforced using trade restrictions, should trade restrictions be used to enforce Kyoto's successor? The idea is tempting. President Sarkozy of France has suggested that trade restrictions be considered. Nobel-prizewinning economist Joseph Stiglitz has recommended that they be used. ${ }^{10}$

Trade restrictions may serve two purposes - to correct leakage and to promote participation (that is, deter free riding). A "border tax adjustment" would serve the former aim, though it would also help the latter. A blunter instrument would be intended to promote participation, but if it were to succeed in sustaining full participation, it would neutralize leakage in the bargain.

Unfortunately, border tax adjustments would pose practical challenges. They would need to be based on the emissions released in manufacturing traded products. ${ }^{11}$ Calculating these values would be difficult. Two identical products, manufactured in the same country, might have very different "carbon footprints" (depending, for example, on how the electricity used as an input was generated). Cruder calculations might be contemplated, but sector-specific taxes would also be very hard to calculate. ${ }^{12}$ Moreover, as trade restrictions became cruder, they would be less effective at reducing leakage. ${ }^{13}$

Blunter punishments may also fail. Punishments meant only to enforce participation pose other problems. The restrictions would have to be severe in addition to being credible, and punishments typically become less credible as they become more severe. ${ }^{14}$ This is why the Stability and Growth Pact collapsed. Of course, and as mentioned before, the enforcement mechanism underpinning the World Trade Organisation is effective. However, trade is a bilateral activity and climate change is a global public good. Trade restrictions were also used to enforce the provision of another global public good. The Montreal Protocol on Substances that Deplete the Ozone Layer is enforced by a trade restriction. But the nature of this challenge is different from climate change. ${ }^{15}$ Among other differences, Montreal restricts consumption (production plus imports minus exports) and not only production (Kyoto restricts only the emissions released by production). Also, although the Montreal Protocol permitted parties to restrict trade based on whether ozone-depleting substances were released in the manufacture of

\footnotetext{
9 See the Afterword to Barrett (2005).

10 Stiglitz (2006).

11 Even if the domestic policy were not economy-wide, there would be general equilibrium effects, and these would need to be taken into account at the border.

12 For example, Hoel (1996) shows that there is no simple relationship between fossil fuel intensity and the optimal sector-specific carbon tax.

13 See Oliveira-Martins et al. (1992).

14 See Barrett (2005).

15 For a full comparison, see Barrett (2005) and Barrett (2007).
} 
products, experts determined that this was impractical. Fortunately, it was also unnecessary. For climate change, as mentioned previously, such restrictions would be essential. Also for reasons explained previously, they would be very difficult to calculate.

The legitimacy of an agreement enforced by trade restrictions may also be questioned. Who should decide what a particular country ought to be obligated to do? Who should decide the punishment that is appropriate should a country fail to fulfil this obligation? Trade restrictions lacking legitimacy may only spur retaliation-a trade war. Britain's decision to raise the topic of climate change at the United Nations Security Council hints at the possible reaction to adopting trade punishments in a climate change treaty. Three of the other permanent members (China, Russia, and the United States) responded coolly to Britain's decision. Other countries, not represented on the Security Council, reacted angrily; they felt that the issue should have remained with the General Assembly, where every country has one vote. The meeting ended without even a statement let alone a resolution. Were one group of countries to seek to impose a climate agreement on others, backed by the threat of trade restrictions, an even stronger response seems possible if not likely.

Finally, trade restrictions would need to enforce compliance in addition to participation. Otherwise, participation would become a route for avoiding having to reduce emissions. Will parties to a future climate treaty agree to this? Would the parties to Kyoto agree to this, when some of them are already at risk of not complying?

If effective means for enforcing a post-Kyoto treaty of the same design cannot be devised, negotiators must be prepared to consider other options. I consider some below.

\section{Some Suggestions for a New Approach}

Stratospheric ozone and the emission of both ozone depleting substances and their substitutes affect climate change in different ways. A recent study has done the accounting and shown that the overall effect of the Montreal Protocol on greenhouse gases has been helpful. ${ }^{16}$ Indeed, the study calculates that the Montreal Protocol has been, and will continue to be, much more helpful in addressing climate change than the Kyoto Protocol, even assuming that Kyoto is implemented perfectly and with full participation. Already, this study estimates, the Montreal Protocol has reduced greenhouse gas emissions four times as much as the Kyoto Protocol intended to achieve.

Most emission reductions under Kyoto's Clean Development Mechanism (CDM) have involved HFCs, a potent greenhouse gas regulated by Kyoto. Unfortunately, under the CDM, "buyers" have overpaid very substantially. According to one analysis, phase out of HFCs under the CDM will cost $€ 4.6$ billion more than necessary (the cost, according to this analysis, should be less than $€ 100$ million). ${ }^{17}$ The CDM has also created a perverse incentive. HFCs (a greenhouse gas) are produced as a byproduct of manufacturing HCFCs (an ozone depleting substance). Under the CDM, manufacturers earn more by reducing the emission of HFCs than they make producing HCFCs.

\footnotetext{
16 Velders et al. (2007)

17 Wara (2007: 596).
} 
Manufacturers in developing countries have thus stepped up their production of HCFCs in order to profit by cutting back on the HFCs produced as a byproduct.

It is significant that a treaty not intending to address climate change has been more effective at doing so than the Kyoto Protocol. This suggests that Kyoto would have been more effective had it been designed differently. Three of the Kyoto gases-HFCs, PFCs, and SF6 - are akin to the substances controlled under the Montreal Protocol (they are also used as refrigerants, for expanding foam, and for insulation). That means that it is very likely that they could all have been controlled and eventually eliminated using an approach like Montreal. This same approach will not work for the other greenhouse gases covered under Kyoto, but because Kyoto lumps all the gases together, opportunities to reduce the emission of the three industrial gases, cost-effectively and globally, were missed. The lesson is that more than one treaty and more than one treaty design may be needed to reduce greenhouse gas emissions.

As noted earlier, addressing climate change fundamentally requires a technological revolution - that is, it requires basic research, development, and diffusion. Kyoto creates very modest "pull" incentives for innovation. Even if these incentives were stronger, however, pull incentives alone will not be able to stimulate a technological revolution. To do that will require basic knowledge- the kind that cannot be patented. Supplying basic knowledge will likely require government funded $\mathrm{R} \& \mathrm{D}$ - a "push" incentive. The returns to investing in basic knowledge, however, will depend in turn on the prospects of technologies embodying this new knowledge being diffused. This is why technology R\&D efforts need to be strategic. ${ }^{18}$ They need to be directed at technologies that will be diffused. Some R\&D can be undertaken unilaterally (when the technology offers national benefits in addition to those related to climate change mitigation). Some R\&D will require international cooperation. An example of the latter kind, with an uncertain and much delayed payoff, is the International Thermonuclear Experimental Reactor being built now in France.

$\mathrm{R} \& \mathrm{D}$ also gets around another problem with the Kyoto approach. Short-term emission targets do not stimulate long-term investment. Nor do they make meeting long-term targets any easier. $R \& D$ has a different effect. It lowers the costs of reducing emissions in the future. Undertaking R\&D now thus increases the abatement that will be undertaken later. Plainly, a post-Kyoto climate agreement must provide both push and pull incentives for R\&D.

The changes brought about by a new treaty also need to be permanent. Kyoto's restrictions end in 2012. After that, even Kyoto's parties are not bound to limit their emissions. This approach not only fails to stimulate innovation. It also creates a substantial risk of backsliding. If the long-term objective is to spark a technological revolution, the incentives must be different. A treaty should ratchet up the actions required with no risk of backsliding. This is what the Montreal Protocol did. It may be difficult for a climate treaty to do this if the goals are expressed as emission limits. It may be easier if the goals are expressed in some other way-such as technology standards. It is sometimes claimed that technology standards have the opposite problem: lock in. However, the evidence suggests otherwise. The oceans have been skilfully protected from oil releases by a succession of technology agreements. ${ }^{19}$ Climate

\footnotetext{
18 Barrett (2006).

19 Barrett (2007).
} 
negotiators would do well to consider the possibilities for this approach in a post-Kyoto treaty.

A new agreement must additionally create incentives for the large, fast-growing to take actions to bring down their emissions. The Bali Action Plan mentions the possibility of developing countries undertaking "nationally appropriate mitigation actions... supported and enabled by technology, financing, and capacity building...." Doing this needs to be a priority.

It needs to be a priority partly for political reasons. Europe has consistently pledged to reduce its emissions by more provided the U.S. and other OECD countries agree to meet the same targets. The U.S., however, has said that it will only act if the fastgrowing developing countries also act. The political challenge is to gather together these contingent promises. So far, they have only been used as excuses for little if any action.

Getting the fast-growing developing countries to reduce their emissions is also essential to meeting any global goals. The emissions of these countries are rising more quickly than the emissions of rich countries. China is now the largest emitter of carbon dioxide in the world. It has vast reserves of coal, and is bringing on line one-to-two coal-fired power plants a week. In a single year, China has added more coal-fired electricity generation capacity than the entire installed capacity of the UK. China's new coal-fired plants have a 40-50 year lifetime. To reduce global emissions significantly during the lifetime of these plants, it may become necessary to retrofit these (and other) plants with carbon capture and storage technology. That technology is not yet developed. R\&D is needed not only to develop the technology but also to demonstrate how the technology can be used in particular contexts (local geology, possibilities for building $\mathrm{CO}_{2}$ pipelines, etc.) and to evaluate its risks (as regards escape but also ecosystem damage for ocean storage). Of course, international finance will also be needed, and providing this is another collective action problem. However, it may be easier to establish technical standards with financing for "incremental costs" as compared with alternative approaches like the CDM. The Montreal Protocol Fund has transferred over $\$ 2$ billion using this same approach.

The Bali roadmap provides an opportunity for fundamental change. According to Bali, the industrialized countries may agree to "quantified emission limitation and reduction objectives," as in Kyoto; or they may agree to undertake "actions.” The latter would presumably include policies such as carbon taxes, sectoral approaches, or technology standards. Actions are critical. Targets and timetables are only of value if they cause countries to take actions to meet them. ${ }^{20}$

The timing of the current negotiation round is awkward. The Bali roadmap charts a course for negotiations that is supposed to end at the Copenhagen conference of the parties, scheduled for December 2009. However, participation by the United States should be a priority for the reasons already mentioned, and a new U.S. administration will not enter office until January 2009. Delays in negotiating a new agreement (or a multiple of agreements) may put even more pressure on Kyoto (making compliance even less likely), but it is more important to negotiate a regime that includes the U.S. than to act quickly.

20 For a range of proposals for a post-Kyoto treaty architecture, including my own, see Aldy and Stavins (2007). 
Treaty ratification by the U.S. requires a two-thirds majority vote by the Senate. This means 66 votes. The threshold for approving domestic legislation is lower-only 60 votes. Treaties are rarely voted down (the last treaty to be voted down was the Comprehensive Nuclear Test Ban Treaty, at the end of the Clinton administration). They are more likely never to be referred to the Senate, should the administration fear rejection (this was Kyoto's fate under the Clinton administration, though it should also be acknowledged that the details of this agreement were not negotiated until after George W. Bush became president).

The mechanics of the U.S. system suggest that, rather than negotiate a treaty limiting emissions and then expecting the U.S. to ratify, it may be preferable for the U.S. to adopt domestic legislation limiting emissions and for the U.S. then to ratify a treaty incorporating the emission limits (or actions) already approved by domestic legislation.

Note, however, that the U.S. Senate may approve a different kind of treaty, and as I have noted before, other kinds of treaty (such as R\&D or technology standards agreements) may be needed to address the fundamental challenge of climate change.

\section{Longer Term Evolution of the Climate Regime}

My attention in this paper has focused on the need to reduce emissions. Of course other actions are also needed, such as for adaptation. But one reason adaptation has been discussed much more in recent years is that the world has failed to bring global emissions under control. This is a reminder that our success or failure in limiting emissions will not simply lead to "climate disaster" as is often claimed. It will lead to other changes.

Adaptation will be favoured because it yields national benefits. The greatest challenge posed by adaptation is getting the rich countries to help finance adaptation by poor countries.

Another approach that may be favoured is "air capture"- that is, technologies that take $\mathrm{CO}_{2}$ directly out of the atmosphere. These technologies do not yet exist even as pilot projects, and they will be expensive to develop and use, but they have two advantages. ${ }^{21}$ The first is that they can be decoupled from energy systems. The second is that they can be undertaken as a single, large project. These technologies, however, raise a new problem for the world. Since air capture can reduce atmospheric concentrations and not only limit their rise, they create a challenge for governance: which countries should be able to decide the level of atmospheric concentrations that is "best"?

One more approach that will appear increasingly tempting is "geoengineering." This approach can offset the warming associated with rising concentrations by reducing the amount of solar radiation that strikes the Earth. Like industrial "air capture" it can be undertaken as a single project. Unlike "air capture," however, some geoengineering technologies are inexpensive. They can also have a near-immediate effect on the climate. Geoengineering is therefore more likely to be used. But geoengineering also poses a number of challenges. It would address the symptoms of climate change, not its causes. It would not address the related problem of ocean acidification. It would entail

21 For a fuller discussion of this technology, see Pielke (2007). 
undertaking a new global experiment to offset another one (rising atmospheric concentrations of greenhouse gases). Most importantly of all, because it is inexpensive, countries may have an incentive to use geoengineering unilaterally. Geoengineering has the opposite problem of reducing emissions: it is too easy to do. ${ }^{22}$ As with air capture, the challenge for geoengineering is governance: which countries should decide whether and under what circumstances geoengineering should be attempted?

22 See Barrett (2007). 


\section{References}

Aldy, J.E., and R.N. Stavins (eds.) (2007). Architectures for Agreement: Addressing Global Climate Change in the Post-Kyoto World. New York: Cambridge University Press.

Barrett, S. (2007). Why Cooperate? The Incentive to Supply Global Public Goods. Oxford: Oxford University Press.

Barrett, S. (2006). Climate Treaties and 'Breakthrough' Technologies. American Economic Review (Papers and Proceedings) 96 (2): 22-25.

Barrett, S. (2005). Environment and Statecraft: The Strategy of Environmental Treaty-Making. Oxford: Oxford University Press (paperback edition).

Government of Canada (2005). Moving Forward on Climate Change: A Plan for Honouring Our Kyoto Commitment. Ottawa: Government of Canada.

Hoel, M. (1996). Should a Carbon Tax Be Differentiated across Sectors? Journal of Public Economics 59: 17-32.

Hoffert, M.I., et al. (2002). Advanced Technology Paths to Global Climate Stability: Energy for a Greenhouse Planet. Science 298: 981-987.

Kallbekken, S., and J. Hovi (2007). The Price of Non-Compliance with the Kyoto Protocol: The Remarkable Case of Norway. International Environmental Agreements 7: 1-15.

Nordhaus, W.D. (2007). A Review of the Stern Review on the Economics of Climate Change. Journal of Economic Literature 45: 686-702.

Oliveira, J., J.-M. Burniaux, and J.P. Martin (1992). Trade and the Effectiveness of Unilateral $\mathrm{CO}_{2}$ Abatement Policies: Evidence from GREEN. OECD Economic Studies, No. 19:123140 .

Pielke, R.A. (2007). Air Capture of Carbon Dioxide: Economic and Political Considerations. Mimeo, University of Colorado.

Stern, N. (2007). Stern Review: The Economics of Climate Change. Cambridge: Cambridge University Press.

Stiglitz, J.E. (2006). A New Agenda for Global Warming. The Economists' Voice 3 (7): Art. 3. Available at: http://www.bepress.com/ev/vol3/iss7/art3.

Velders, G.J.M., S.O. Anderson, J.S. Daniel, D.W. Fahey, and M. McFarland (2007). The Importance of the Montreal Protocol in Protecting Climate. Proceedings of the National Academy of Sciences 104 (12): 4814-4819.

Wara, M. (2007). Is the Global Carbon Market Working? Nature 445: 595-596. 


\section{Conomics}

The Open-Access, Open-Assessment E-Journal

\section{Please note:}

You are most sincerely encouraged to participate in the open assessment of this article. You can do so by either rating the article on a scale from 1 (bad) to 5 (excellent) or by posting your comments.

Please go to:

www.economics-ejournal.org/economics/journalarticles/2009-5

The Editor 